\title{
Glucose Tolerance and Physical Fitness: An Epidemiologic Study in an Entire Community*
}

\author{
Henry J. Montoye ${ }^{1}$, Walter Block ${ }^{2}$, Jacob B. Keller ${ }^{2}$, and Park W. Willis, III ${ }^{3}$ \\ ${ }^{1}$ School of Health, Physical Education and Recreation, University of Tennessee, \\ Knoxville, Tennessee 37916, USA \\ ${ }^{2}$ Department of Epidemiology, School of Public Health, University of Michigan, \\ Ann Arbor, Michigan 48104, USA \\ 3 Section of Cardiology, Department of Internal Medicine, University of Michigan Medical \\ School, \\ Ann Arbor, Michigan 48104, USA
}

\begin{abstract}
Summary. A modification of the Harvard Step Test was administered to approximately 4700 males and females, age 10-69 in Tecumseh, Michigan. Heart rate response to this standardized exercise test is an estimate of capacity for muscular work. A blood sample was drawn $1 \mathrm{~h}$ after a glucose challenge on the same day the exercise test was given. Four skinfolds were measured as an index of body fatness. It was the purpose of this analysis to study the relationship of glucose tolerance to heart rate response to exercise.

All analyses were done in age and sex-specific sub-groups. The correlation coefficients are low but positive in all but one sub-group and half of the coefficients are statistically significant. This suggests that poor fitness for work (high heart rate in response to exercise) was related, albeit weakly, to lowered glucose tolerance. However, there is a positive relationship between body fatness on the one hand and serum glucose and heart rate response to exercise on the other. When the effect of body fatness was eliminated the relationship of heart rate response to exercise and glucose tolerance remained about the same; low but statistically significant in some age groups.
\end{abstract}

Key words: Glucose tolerance - Diabetes - Exercise - Physical activity Exertion - Fitness - Step test - Skinfolds.

\section{Introduction}

The Tecumseh Community Health Study has been described in detail elsewhere [2, 8]. Briefly it is a longitudinal study of a total community, initiated in 19.57 to determine epidemiological factors influencing health and disease in Tecumseh, a city in southeastern Michigan, USA. During 1959 and 1960, 8641 persons or $88 \%$ of the total population participated in Phase I which included a medical interview, physical

* Supported in part by Program Progress Grant Number HE-09814 from the National Institutes of Health, U.S. Public Health Service to the University of Michigan and the Tennessee Heart Association Grant to the University of Tennessee 
examination, and laboratory tests but no exercise test. In 1962-1965 residents of Tecumseh, and persons examined in Phase I who had moved to nearby areas, were invited to participate in Phase II which included 9226 persons. Genetic influences and the biological, physical, and social environment are being studied to determine how these factors interact to maintain the health of some individuals and to cause others to become susceptible to disease. Heart disease, diabetes, pulmonary disease and arthritis have received considerable attention in the Tecumseh study. Glucose tolerance is related to diabetes and cardiovascular disease [2, 13]. In fact, glucose tolerance is one of the diagnostic tests for diabetes.

It was of interest to obtain a simple estimate of fitness for muscular work in the Tecumseh respondents to study the relationship of fitness to health and disease. During Phase II a modification of the Harvard Step Test [1] was administered to most of the respondents, age $10-69$. It is the purpose of the present paper to report the relationship of the scores on this test to glucose tolerance.

\section{Methods}

Approximately $82 \%$ of all the residents in the study area participated in the second series of examinations. The respondents came to the clinic, usually in family groups, at which time they were given physical examinations.

The adult participants were given $100 \mathrm{~g}$ of glucose; young children, $50 \mathrm{~g}$. One hour after glucose challenge, venous blood was drawn. The examining physician obtained a history of recent meals and snacks, specifying the time and amount of each item of food taken in the four hours preceding arrival at the clinic. The amount of carbohydrate consumed in each of the last four hours was estimated from these records by a dietitian using standard tables. Blood glucose concentrations were determined by the Hoffman method on the autoanalyzer. The glucose concentration was then corrected for age, sex, and length of time since last meal by regression analysis. The resulting "glucose scores" have a mean of ten and a standard deviation of one. Details of these procedures have been published $[3,4]$.

On the same visit to the clinic at which the blood sample was taken, a modification of the Harvard Step Test [1] was administered in an air conditioned laboratory to all males and females, age 10-69, who were not excluded for medical reasons. Pregnant women were excluded. Thus, about $84 \%$ of the respondents were given the test. The step test required the subjects to step onto an 8-inch bench at the rate of 24 steps ( 4 count sequences) per minute for $3 \mathrm{~min}$. This is an energy expenditure roughly equivalent to five times the basal metabolic rate [11]. The heart rate was determined from the electrocardiogram which was recorded with the subject sitting before the exercise, during the exercise, and for $5 \mathrm{~min}$ after the exercise while the subject was again sitting. Details of the step test, including age relationships, have been published $[9,10]$. A high heart rate indicates poorer fitness. Subjects over age 64 were excluded from this analysis. Also, a few subjects were unable to maintain the stepping rate and for some a glucose score was not available. Thus the glucose tolerance - step test analyses were based on 2385 males and 2318 females.

During the same visit to the clinic, skinfold thickness was measured at four sites, triceps, subscapular, abdomen and waist, using the Lange Caliper. The sum of the four skinfolds was used as an estimate of body fatness. The caliper was calibrated regularly by means of small springs with known forcecompression curves.

\section{Results}

Although glucose scores were adjusted for age and sex, heart rates during and after exercise in the Tecumseh population are age and sex related. Therefore, all analyses were done separately for males and females within narrow age groups. Table 1 
Table 1. Correlation coefficients: Blood glucose score, heart rate response to exercise ( $2 \min 30 \mathrm{~s})$ and sum of skinfolds

\begin{tabular}{|c|c|c|c|c|c|}
\hline \multirow{2}{*}{$\begin{array}{l}\text { Age } \\
\text { groups }\end{array}$} & \multirow[t]{2}{*}{$N$} & \multicolumn{3}{|c|}{ Correlation coefficients } & \multirow{2}{*}{$\begin{array}{l}\text { Partial correlation } \\
\text { coefficients } \\
\text { glucose vs heart } \\
\text { rate with effect } \\
\text { of skinfold remove }\end{array}$} \\
\hline & & $\begin{array}{l}\text { Heart rate } \\
\text { with } \\
\text { glucose }\end{array}$ & $\begin{array}{l}\text { Heart rate } \\
\text { with } \\
\text { skinfolds }\end{array}$ & $\begin{array}{l}\text { Glucose } \\
\text { with } \\
\text { skinfolds }\end{array}$ & \\
\hline \multicolumn{6}{|l|}{ Males } \\
\hline $10-11$ & 211 & $0.16^{\mathrm{a}}$ & $0.36^{b}$ & 0.04 & $0.15^{\mathrm{a}}$ \\
\hline $12-13$ & 191 & 0.12 & $0.42^{b}$ & 0.11 & 0.09 \\
\hline $14-15$ & 174 & 0.12 & $0.39^{b}$ & 0.07 & 0.10 \\
\hline $16-19$ & 272 & 0.06 & $0.32^{b}$ & 0.03 & 0.06 \\
\hline $20-24$ & 202 & 0.12 & $0.29^{b}$ & 0.11 & 0.09 \\
\hline $25-34$ & 444 & $0.22^{b}$ & $0.21^{\mathrm{b}}$ & $0.14^{\mathrm{a}}$ & $0.19^{\mathrm{b}}$ \\
\hline $35-44$ & 488 & $0.16^{\mathrm{b}}$ & $0.19^{\mathfrak{b}}$ & $0.14^{\mathrm{a}}$ & $0.14^{\mathrm{b}}$ \\
\hline $45-54$ & 249 & $0.13^{\mathrm{a}}$ & 0.04 & 0.05 & $0.13^{\mathrm{a}}$ \\
\hline $55-64$ & 116 & $0.20^{\mathrm{a}}$ & 0.02 & 0.07 & $0.20^{\mathrm{a}}$ \\
\hline \multicolumn{6}{|l|}{ Females } \\
\hline $10-11$ & 173 & 0.10 & $0.27^{\mathrm{b}}$ & -0.11 & 0.13 \\
\hline $12-13$ & 182 & 0.12 & $0.45^{b}$ & -0.06 & $0.17^{\mathrm{a}}$ \\
\hline $14-15$ & 161 & $0.22^{\mathrm{b}}$ & $0.32^{b}$ & 0.00 & $0.23^{b}$ \\
\hline $16-19$ & 243 & 0.11 & $0.26^{\mathrm{b}}$ & 0.12 & 0.08 \\
\hline $20-24$ & 215 & -0.04 & $0.25^{b}$ & 0.05 & -0.05 \\
\hline $25-34$ & 473 & $0.19^{\mathrm{b}}$ & $0.30^{\mathrm{b}}$ & $0.11^{\mathrm{a}}$ & $0.17^{\mathrm{b}}$ \\
\hline $35-44$ & 497 & $0.16^{\mathrm{b}}$ & $0.25^{b}$ & $0.10^{\mathrm{a}}$ & $0.14^{\mathrm{b}}$ \\
\hline $45-54$ & 221 & 0.07 & $0.15^{\mathrm{a}}$ & $0.20^{\mathrm{b}}$ & 0.04 \\
\hline $55-64$ & 83 & $0.23^{\mathrm{a}}$ & -0.04 & 0.07 & 0.23 \\
\hline
\end{tabular}

a Statistically significant, $p 0.05$

b Statistically significant, $p 0.01$

contains correlation coefficients expressing the relationship between glucose score and heart rate during exercise ( $2 \min 30 \mathrm{~s}$ ). The relationship is not impressive even though all but one of the coefficients are positive (i.e., poorer fitness with higher glucose) and nine of the 18 coefficients are statistically significant at a probability of 0.05 or less.

However, the possibility exists that the step test score and glucose score are related, albeit weakly, only because each is related to body fatness. Table 1 also contains correlation coefficients expressing the relationship between body fatness (sum of four skinfolds) and glucose score and also between fatness and heart rate response to exercise. To investigate this further, the distributions of subjects within each age-sex group were divided into thirds on the basis of the sum of four skinfolds. This was done using all respondents, not only those who took the exercise test. It appears that fewer of the older fatter women took or completed the exercise test. The average glucose score and heart rate responses for the three fatness sub-groups are shown in Figures 1 and 2. Clearly fatter people at most ages tend to have higher exercise and post-exercise heart rates. There is only a trend for the fatter subjects to have higher glucose scores. The question can be raised: Does the tendency for higher glucose score in the less fit subjects only reflect their greater fatness. 

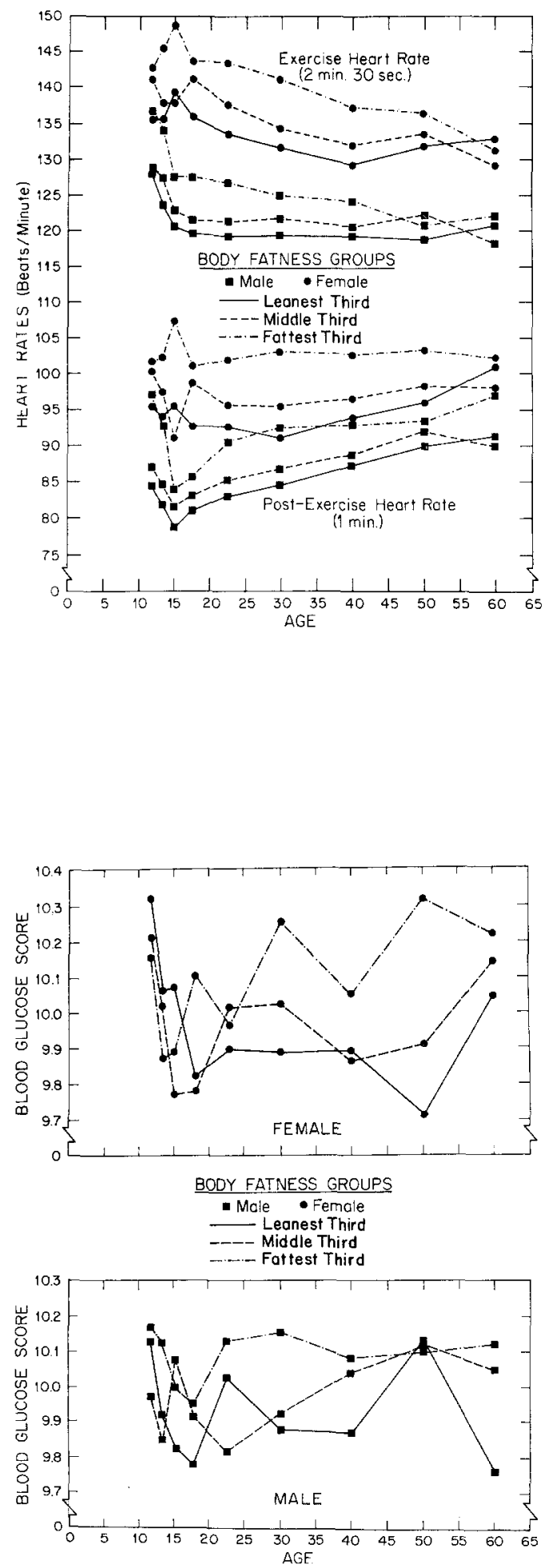

Fig. 1. Mean heart rate response to exercise in three body fatness groups in males and females
Fig. 2. Mean glucose tolerance scores in three body fatness groups. The score is derived by adjusting the glucose tolerance for age, sex, and length of time since last meal 
In order to take out the effect of body fatness, partial correlation coefficients were calculated, i.e., heart rate vs. glucose score with the linear effect of sum of skinfolds removed. These values are also shown in Table 1 . These coefficients are again similar to the zero-order coefficients. All but one is positive and five of the eighteen are statistically significant.

All the analyses were repeated with heart rate one minute after exercise replacing the exercise heart rate. The results were almost the same. This is not unexpected since heart rate during and one minute after a standard exercise are highly correlated [10].

\section{Discussion}

The relationship of plasma glucose or glucose tolerance to physical fitness has received little attention. Oberman and colleagues in 1965 reported the intercorrelations of a number of variables in 600 men, age 42-62 [12]. One of these variables was the heart rate immediately after a modified Harvard Step Test ( 3 min at 20 steps $/ \mathrm{min}$ ). This is similar to the test used in the present study. Coefficients of correlation expressing the relationship to fasting blood glucose and glucose tolerance (blood glucose $2 \mathrm{~h}$ after $100 \mathrm{~g}$ challenge) were both 0.15 . Both are statistically significant $(p<0.01)$ and almost identical to our values for males of the same age group. Correlation coefficients of glucose tolerance with skinfolds ranged from $0.08-0.14$. All but one are statistically significant $(p<0.01)$ and not much different from those in the present study. If one statistically removes the effect of body fatness, there is little effect on the relationship of exercise heart rate to glucose tolerance in Obermans study.

Hollister and others [5] reported a correlation coefficient of 0.14 , similar to our finding, between fasting blood glucose and triceps skinfolds in 104 male psychiatric patients. It has been reported previously that larger skinfolds are associated with poorer fitness, i.e., higher heart rate in response to a standard step test $[6,12]$ and these correlation coefficients were also similar to ours.

There are problems with using the modified Harvard Step Test as a measure of fitness. It is difficult, in some cases, to require subjects to maintain the proper cadence. Furthermore, heart rate response to sub-maximal exercise is not a precise measurement of metabolic capacity [7]. On the other hand, data being prepared for publication in which a treadmill test was used gave results similar to those with the step test.

It is possbile that had the glucose challenge been calculated on the basis of body weight and had the subjects been in a post-absorptive state, more precise data would have been available for analysis. However, these procedures were not possbile in this epidemiologic study.

In conclusion, it appears that when the effects of body fatness are removed, the variance in heart rate response to exercise (fitness) accounts for less than 4 or $5 \%$ of the variance in glucose tolerance. 


\section{References}

1. Brouha, L.: The step test: a simple method of measuring physical fitness for muscular work in young men. Res. Quart. 14, 31-36 (1943)

2. Epstein, F. H.: An epidemiological study in a total community: the Tecumseh project. Univ. Mich. med. Bull. 206, 307-314 (1960)

3. Hayner, N. S.: The one-hour oral glucose tolerance test. Nat. Center for Health Statistics, 1963. Public Health Service Publication No. 1000-Series 2-No. 3

4. Hayner, N. S., Kjelsberg, M. D., Epstein, F. H., Francis, T., Jr.: Carbohydrate tolerance and diabetes in a total community, Tecumseh, Michigan. 1. Effects of age, sex, and test conditions on one-hour glucose tolerance in adults. Diabetes 14, 413-423 (1965)

5. Hollister, L. E., Overall, J. E., Snow, H. L.: Relationship of Obesity to serum triglyceride, cholesterol and uric acid and plasma glucose levels. Amer. J. clin. Nutr. 20, 777-782 (1967)

6. Johnson, R. H., Walton, J. L.: Fitness, fatness, and post-exercise ketosis. Lancet $1971 \mathrm{I}$, 566-568

7. Montoye, H. J.: Circulatory-respiratory fitness, Chapt. 3. In: An introduction to measurement in physical education, Vol. 4, Physical fitness, Indianapolis: Phi Epsilon Kappa Fraternity 1970

8. Montoye, H. J.: Physical activity and health: An epidemiologic study of an entire community. Englewood Cliffs, New Jersey: Prentice-Hall 1975

9. Montoye, H. J., Willis, P. W., III, Cunningham, D. A.: Heart rate response to submaximal exercise: relationship of age and sex. J. Geront. 23, 127-133 (1968)

10. Montoye, H. J., Willis, P. W., III, Cunningham, D. A., Keller, J. B.: Heart rate response to a modified Harvard Step Test: males and females age 10-69. Res. Quart. 40, 153-162 (1969)

11. Nagle, F. J., Balke, B., Naughton, J. P.: Graduational step test for assessing work capacity. J. appl. Physiol. 20, 745-748 (1965)

12. Oberman, A., Lane, N. E., Mitchell, R. E., Graybiel, A.: The thousand aviator study. Monograph No. 12, U.S. Aerospace Medical Institute, Pensacola, Fla. 1965

13. Ostrander, L. D., Francis, T., Jr., Hayner, N. S., Kjelsberg, M. O., Epstein, F. H.: The relation of cardiovascular disease to hyperglycemia. Ann. intern. Med. 62, 1188-1198 (1965) 